\title{
Distribution of extracellular matrix components in the developing ruminant corpus luteum: a wound repair hypothesis for luteinization
}

\author{
L. M. Silvester and M. R. Luck \\ Division of Animal Physiology, School of Biological Sciences, University of Nottingham, Sutton Bonington Campus, \\ Loughborough, Leicestershire LE12 5RD, UK
}

\begin{abstract}
The aim of this study was to investigate corpus luteum development by visualization of extracellular matrix proteins in the tissue at sequential stages of the luteal phase. Corpora lutea were collected from oestrus-synchronized sheep and from bovine material from an abattoir. The distributions of collagen types I and IV, fibronectin and von Willebrand factor were determined using immunohistology and semi-quantitative image analysis. During the post-ovulatory period, a fibronectin- and von Willebrand factor-rich matrix occurred centrally, adjacent to the inner parenchymal surface, whereas during early luteal development a clear border of fibronectin separated the inner parenchyma from the lumen. The inner parenchyma had abundant fibronectin initially, but the amount decreased as the rate of organ growth decreased. Over the same period, the amount of collagen type I first increased and then decreased. Collagen type I and fibronectin were less abundant in other regions of the parenchyma, and the general pattern was of slightly increasing amounts of collagen type $I$ and decreasing amounts of fibronectin as luteal development proceeded. In contrast to earlier studies, only a small percentage of large luteal cells was found to have an associated layer of collagen type IV (presumed basal lamina). It is concluded that luteal growth and maturation require organized sequences of tissue remodelling. The central meshwork of fibronectin and von Willebrand factor and sequential deposition of collagen type I and fibronectin are strongly reminiscent of events in granulation tissue. This indicates that luteinization may be best understood as a wound repair-like process that succeeds the inflammation-like events of ovulation.
\end{abstract}

\section{Introduction}

The development of a corpus luteum involves remodelling of the follicular tissue that remains after ovulation and de novo tissue formation, as well as alteration of some cell phenotypes (Luck, 1994). As most tissues have an extracellular matrix (ECM), the formation and subsequent maturation of this material must be an integral component of the development of any new structure.

Currently, there is little information regarding the composition of the luteal ECM and nothing is known about its organization or development. Various ultrastructural studies have observed fibrillar collagen in the ruminant luteal parenchyma on the basis of morphology (Deane et al., 1966; Gemmell et al., 1974; Parry et al., 1980; Archbald et al., 1981). Histochemical studies have reported the presence of 'collagens' in the luteal tissue of ewes (Hadek, 1958) and cows (Donaldson and Hansel, 1965; Priedkalns et al., 1968; Shiina, 1990; Parkinson et al., 1994). None of these studies was able to discern which of the 19 known types of collagen

Received 19 August 1998.
(Hulmes, 1992; Myers et al., 1997; Saarela et al., 1998) were present. Ruminant luteal tissue contains collagen type I, collagen type IV, fibronectin and laminin (Luck and Zhao, 1993; Luck et al., 1995; Zhao and Luck, 1995). The mRNAs for these ECM components have also been detected in bovine luteal tissue (Zhao and Luck, 1995). The ovine luteal capsule is rich in collagen type I (Luck et al., 1995).

A key function of collagen is in the formation of basal laminae. Key components of basal laminae include collagen type IV and laminin, neither of which is present in any other ECM structure (Mercker, 1994). Although collagen type IV protein and mRNA have been detected in ruminant luteal tissue, there is no information regarding its distribution (Luck et al., 1995; Zhao and Luck, 1995). There are two probable locations for collagen type IV in luteal tissue: in the basal lamina of blood vessels and around large luteal cells. Ruminant luteal tissue is known to contain an extensive capillary bed (Redmer and Reynolds, 1996). Ultrastructural studies detected a basal lamina-like structure around large luteal cells in cattle (Fields et al., 1985, 1992; O'Shea et al., 1990; Sawyer, 1995) and sheep (Deane et al., 1966; O'Shea et al., 1979; Farin et al., 1986; Kenny et al., 1989), although basal 
lamina-specific components have not been demonstrated. Consequently, a systematic analysis of the extent to which large luteal cells are surrounded by a basal lamina, and the distribution of basal lamina in the luteal parenchyma was considered necessary.

Superficial support for regarding luteinization as a wound repair-like process comes from the observation that the follicle shows a luminal blood clot soon after rupture. This site may fill with tissue to a lesser or greater extent as the corpus luteum grows (Deichert et al., 1987). Follicular fluid possesses the components of the extrinsic coagulation system (Yamada and Gentry, 1995) and thus may contribute to the formation of these clots. Studies of women with von Willebrand's disease (a hereditary deficiency of von Willebrand factor, which is an important component of normal clot formation; Ruggeri, 1991) report a high frequency of intermenstrual corpus luteum bleeding (Silwer, 1973) possibly due to abnormal luteal development. Corner (1956) studied human post-ovulatory (less than $24 \mathrm{~h}$ after ovulation) tissue and described the presence of a fine 'fibrin network'. If this fibrin network is similar to that formed by the haemostatic process after tissue damage, it would be reasonable to expect extracellular von Willebrand factor to be present in ruminant luteal tissue immediately after ovulation. von Willebrand factor has been observed in bovine (Zheng et al., 1993) and ovine (Jablonka-Shariff et al., 1993; Luck et al., 1995) mature luteal tissue as an endothelial cell marker, but no observations have been made of postovulatory tissue.

The aims of this study were: (i) to determine the distribution of collagen type I and fibronectin in identified regions of bovine and ovine luteal parenchyma during different periods of the luteal phase; (ii) to examine bovine postovulatory luteal tissue for evidence of fibronectin and von Willebrand factor in a clot structure; (iii) to determine the extent to which ovine large luteal cells are surrounded by a basal lamina (collagen type IV); and (iv) to use these observations to draw some initial conclusions about the likely pattern of tissue development in the ruminant corpus luteum.

\section{Materials and Methods}

\section{Animals and tissue preparation}

Twenty multiparous Mule ewes were loose winter housed and fed silage. The animals were also provided with water and hay ad libitum. Each animal received two intramuscular bolus injections containing $125 \mu \mathrm{g}$ Cloprostenol (Estrumate; Malinckrodt Veterinary Ltd, Uxbridge) at 10 day intervals. On days 5, 8, 10, 12 and 15 after the second Cloprostenol injection, four animals were killed and the ovaries were removed. The ovaries were collected on days 2, 5, 7, 9 and 12 of the luteal phase, respectively (Acritopoulou et al., 1978). An ovary bearing one corpus luteum was selected from each ewe and was bisected along the basal-apical axis. One half of the luteal tissue was dissected out and weighed to estimate the total mass of each corpus luteum.

Bovine ovaries were obtained from an abattoir from animals of a Fresian breed, but of unknown age and stage of the oestrous cycle. They were classified according to morphological criteria and mass (Ireland et al., 1980) as early luteal phase, early mid-luteal phase, late mid-luteal phase or late luteal phase. Five corpora lutea (five animals) were selected from each group. Luteal tissue from five Fresian cows that had ovulated in the $24 \mathrm{~h}$ before they were killed was also made available (courtesy of G. E. Mann, University of Nottingham) and denoted as post-ovulatory. The bovine corpora lutea were excised from the ovaries, weighed and bisected along the basal-apical axis.

A $4 \mathrm{~mm}$ tissue slice was removed from the bisected surface of each bovine corpus luteum and ovine ovary. A $4 \mathrm{~mm}$ section of ovine carotid artery (abattoir material) was collected for use as quality control tissue for the collagen type I and fibronectin immunohistology. All tissues were fixed in $10 \%$ buffered formol saline for $96 \mathrm{~h}$ with continual gentle agitation. After dehydration through graded alcohols $(70-100 \%)$ and toluene, the tissues were embedded in paraffin wax. Tissue slices of $4 \mu \mathrm{m}$ were placed on slides coated with aminopropyltriethoxysilane (Sigma-Aldrich Company Ltd, Poole). All reagents were analytical reagent (AR) grade and all solvents were standard laboratory reagent (SLR) grade, and were obtained from Fisher Scientific, Loughborough, unless otherwise stated.

\section{Immunohistology}

Immunohistology was conducted in several batches for each antiserum, and each batch contained luteal or ovarian tissue from only one species. Each batch included three quality control slides, one of which was treated with normal rabbit serum and was the first slide in each batch. The other two quality control slides, treated with the appropriate antiserum for the batch, were the second and last slides in each batch. The antisera to collagen type I (Pasteur Institute, Lyon; Ricard-Blum et al., 1985) and fibronectin (Dako, High Wycombe) was evaluated to determine the optimum dilution for maximal immunostaining of a region of luteal tissue (capsule) containing these antigens in abundance (Silvester, 1997). Similarly, the anti-rabbit-horseradish peroxidase (HRP) conjugate (ICN Biomedical, Thame) dilution was optimized for maximal immunostaining in conjunction with optimal first antibody dilutions.

The immunohistology protocol was as described by Silvester (1997). Briefly, after rehydration the tissues were washed three times with water and were then placed in water at $37^{\circ} \mathrm{C}$ for $30 \mathrm{~min}$. The tissue sections were treated with $0.01 \%(\mathrm{w} / \mathrm{v})$ trypsin (Sigma-Aldrich Company Ltd, Poole) in $0.1 \%(\mathrm{w} / \mathrm{v})$ calcium chloride at $\mathrm{pH} 7.4$ for $15 \mathrm{~min}$ at $37^{\circ} \mathrm{C}$. After three washes with distilled water, the slides were placed in $3 \%(\mathrm{v} / \mathrm{v})$ hydrogen peroxide for $5 \mathrm{~min}$. The slides were then washed three times and were placed in prewarmed Tris-buffered saline (TBS: $50 \mathrm{mmol}$ Tris $1^{-1}, 0.8 \%$ $(\mathrm{w} / \mathrm{v})$ sodium chloride, $\mathrm{pH} 7.8)$ at $25^{\circ} \mathrm{C}$ for $30 \mathrm{~min}$. All subsequent incubations, washes and colour development were conducted at $25^{\circ} \mathrm{C}$ using prewarmed reagents. The incubations with sera or antisera were conducted in a humidified chamber at $25^{\circ} \mathrm{C}$. Tissue sections were treated with $20 \%(\mathrm{v} / \mathrm{v})$ normal donkey serum in TBS for $30 \mathrm{~min}$. 


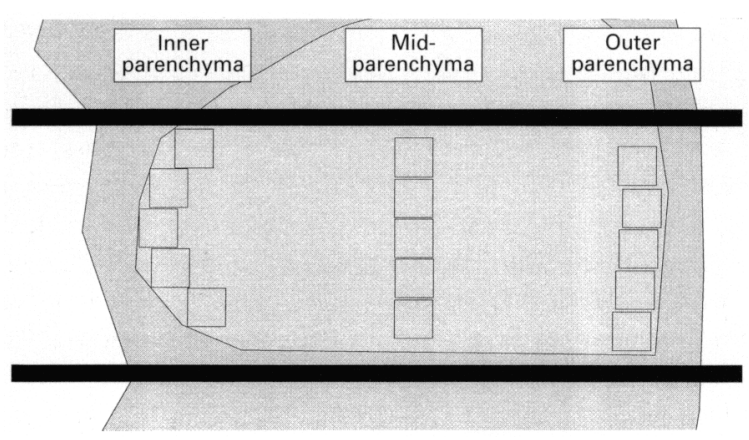

Fig. 1. A transect across the luteal parenchyma showing the position of image analysis fields of view in three regions of the luteal parenchyma (not to scale).

After three $5 \mathrm{~min}$ washes with incubation buffer $(50 \mathrm{mmol}$ Tris $1^{-1}, 0.8 \%(\mathrm{v} / \mathrm{v})$ sodium chloride, $1 \%(\mathrm{v} / \mathrm{v})$ Triton- $\mathrm{X} 100$, $1.5 \%(\mathrm{w} / \mathrm{v}) \mathrm{BSA}, \mathrm{pH} 7.8)$, the slides were treated for $60 \mathrm{~min}$ with primary antiserum or normal rabbit serum (negative control), as appropriate, diluted 1:200 in incubation buffer. After three 5 min washes with incubation buffer, the slides were treated for $30 \mathrm{~min}$ with anti-rabbit-HRP conjugate (ICN-Flow, Thame) diluted 1:300 with incubation buffer. Finally, after three $5 \mathrm{~min}$ washes with TBS, the tissue was treated with diaminobenzidine (DAB) colour reagent (Amenta and Martinez-Hernandez, 1987) in TBS buffer for 10 min, washed five times in distilled water, dehydrated and mounted with DePeX (BDH, Poole).

The collagen type IV and von Willebrand factor immunohistology was conducted using the same protocol except that all incubations with sera or antisera were carried out at room temperature. The collagen type IV (Pasteur Institute, Lyon; Mauger et al., 1987) and von Willebrand factor (Dako, High Wycombe) antisera were both used at a dilution of 1:100. Slides processed for the immunofluorescent detection of ovine collagen type IV were not dehydrated, but were covered with coverslips mounted using an aqueous medium (Vectashield; Vector Laboratories Ltd, Peterborough). The distribution of ovine collagen type IV was determined using a anti-rabbit-fluorescein isothiocyanate conjugate (Sigma, Poole) diluted 1:100 and observed microscopically (Optiphot 2, Nikon, Kingston upon Thames) using a linescanning confocal laser imaging head (Viewscan DVC-250, BioRad, Hemel Hempstead).

\section{Image analysis}

The image analysis was carried out as described by Silvester (1997). The slides with immunostaining for collagen type I and fibronectin were observed using a microscope (Dialux 20EB, Leitz, Milton Keynes) fitted with a $\times 40$ objective and powered from a stabilized source. Images from a colour video camera (TK-870E; JVC, London) were captured and analysed using a computer-based imaging system (Solitaire, SeeScan, Cambridge, UK). The imaging system was optimized to detect DAB staining and calibrated; each of the analysis fields of view had an area of $25970 \mu^{2}$. The imaging system was able to determine the percentage surface area of the field of view that was immunostained, as well as the percentage intensity of the immunostaining (expressed as a proportion of 1 ).

By visual examination, a transect approximately $4 \mathrm{~mm}$ wide was marked from the centre of the corpus luteum to the periphery, across a luteal lobe tangential to the apical-basal axis (Fig. 1). Within the marked transect, various luteal regions were identified by microscopic examination. The internal periphery of the luteal parenchyma was defined as the region closest to the centre of the tissue that contained cells with the morphology of large luteal cells. Areas of loose connective tissue or other regions containing no obvious large luteal cells were not considered to be parenchymal. The external periphery of the luteal parenchyma was defined as the region furthest from the centre of the corpus luteum, adjacent to the luteal capsule. The mid-parenchyma of the luteal tissue was selected as a region that was geometrically central to the external and internal periphery. Within each of the defined regions, five fields of view were analysed, giving a total analysis area of $129850 \mu^{2}$. The initial field of view was chosen randomly and, whenever possible, the remaining four were sequentially adjacent to it. When a field of view contained large blood vessels or substantial acellular regions, an adjacent field of view was selected for analysis.

The degree of non-specific staining for each animal was determined using five random observations of the luteal region on the respective negative reagent control slides. The degree of staining was calculated as the percentage surface area of staining multiplied by the intensity of staining. The tissue content of each antigen was corrected by subtraction of the respective non-specific staining value and expressed as a mean area density ( \pm SEM) for each region at a given day or period of the luteal phase.

\section{Collagen type IV image analysis}

In each tissue, a transect at right angles to the luteal apical-basal axis and passing through the parenchyma of a single luteal lobe was selected. Along each transect, a continuous series of dark- and light-field photographs was taken from the outer to the inner parenchyma. The tissue in each photographic transect was divided into regions 1-10, $11-50,51-90$ and $91-100 \%$ of the distance from the outer to the inner edge of the tissue. In each region, all of the cells that had the morphology of large luteal cells (that is, large polyhedral cells), a visible nucleus and were fully within a described region were identified. The large luteal cells with collagen type IV around the periphery were classified according to whether the collagen type IV immunofluorescence extended less than or more than halfway around each cell. All collagen type IV that was obviously associated with a blood vessel was classified as endothelial basal lamina and excluded from the analysis. The results for both classes of large luteal cell with collagen type IV around the periphery were expressed as a proportion of the total number of large luteal cells identified in each region. 

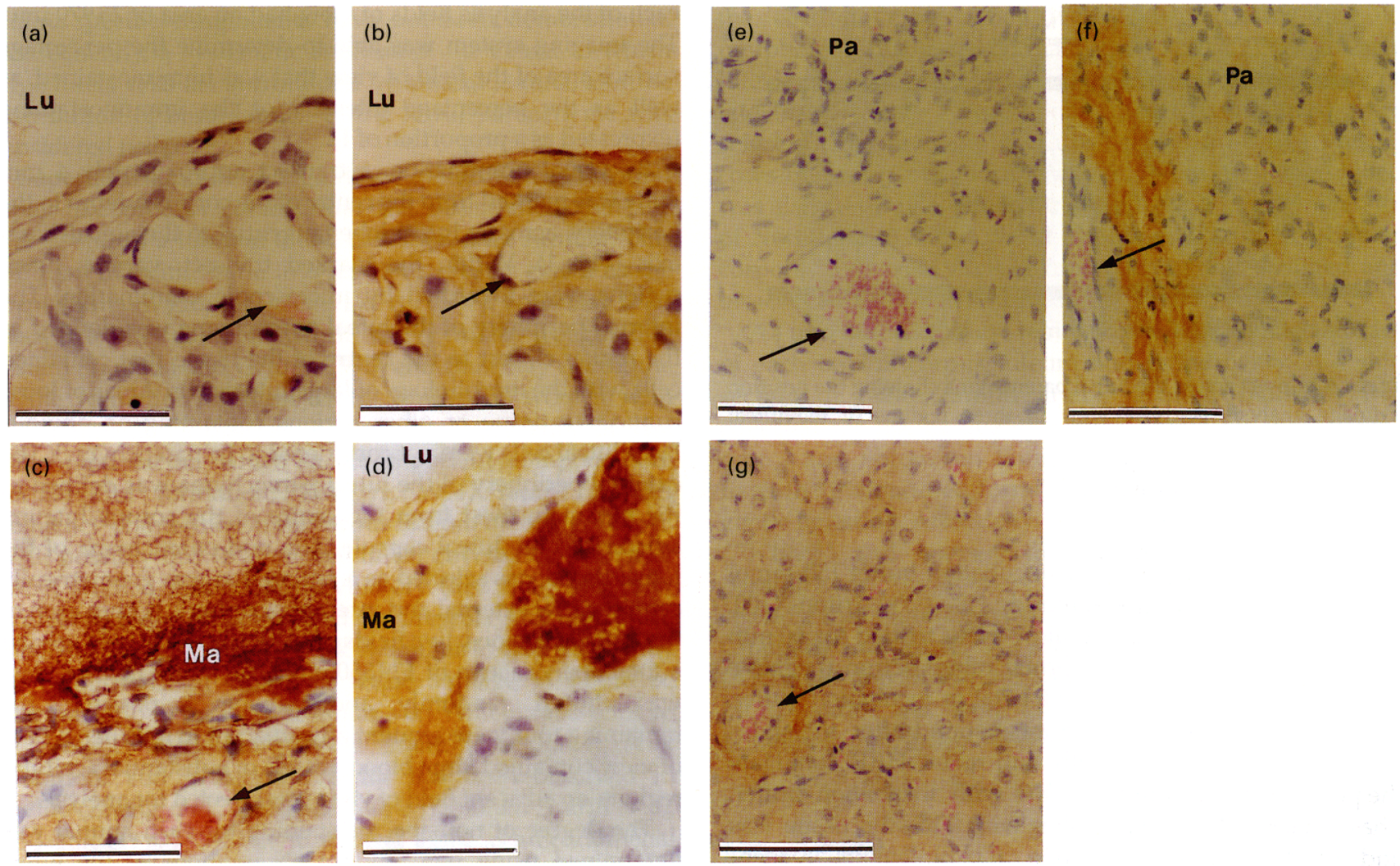

Fig. 2. Immunostaining of bovine luteal tissue during stages of the luteal phase. (a-d) Post-ovulatory tissue, (e-g) late mid-luteal phase tissue. The distribution of extracellular matrix components in the luteal tissue is indicated by orange-brown staining. (a,e) Control slides treated with normal rabbit serum in place of antisera. In the post-ovulatory tissue, there were negligible amounts of collagen type I at the luminal periphery of the inner parenchyma (b), whereas copious amounts of fibronectin were present at the luminal edge and in a disorganized matrix that extended into the lumen (c), which also contained von Willebrand factor (d). The homogeneous distribution of fibronectin and collagen type I in the outer and mid-parenchymal regions in all the observed stages of the luteal phase is illustrated by the distribution of collagen type I (f) and fibronectin (g) in the mid-parenchymal region of late mid-luteal phase tissue. Arrows show blood vessels; Lu, luteal lumen; Ma, luminal matrix adjacent to inner parenchyma; Pa, parenchyma. Scale bars represents $50 \mu \mathrm{m}$.

\section{Statistical analyses}

Chi-squared tests were performed between the observed and theoretical frequency distributions to determine whether the image analysis data corresponded to a normal distribution. The image analysis data for the collagen type I and fibronectin studies were pooled from the two species to create large data sets for construction of observed and theoretical distributions. The range of each class was an area density of five, providing eight classes in each test. From the mean and standard deviation for each set of data, the expected frequency distributions were generated using the scheme given by Hughes and Grawoig (1971).

One-way analysis of variance (ANOVA) was used to determine the source of the variance in the image analysis data for both antigens and in the luteal masses for both species. The source of the variance for the different luteal tissue regions in the same period, or day of the luteal phase, and for the same luteal tissue regions within different periods or days of the luteal phase for both antigens in both species, was also determined by one-way ANOVA. The residual mean square from each ANOVA test was used to calculate the standard error of the difference given in Tables 1-5.
The significance of differences among adjacent days and periods of the luteal phase within luteal regions, among adjacent luteal regions within days and periods of the luteal phase, and among luteal masses on adjacent days and periods of the luteal phase were determined using Student's $t$ test. Means and standard errors of means were calculated for the different regions on the days and periods of the luteal phase for both species.

\section{Results}

\section{General morphology}

All of the post-ovulatory bovine corpora lutea contained coagulated blood in the lumen at the centre of the tissue. In addition, all had a prominent rupture point at the ovarian surface that was rich red and showed no evidence of epithelial cover. One-way ANOVA of the bovine and ovine luteal masses showed that variation was greater between the luteal stage groups than within them $(P<0.01$ and $<0.001$, respectively). Bovine luteal mass increased significantly from 

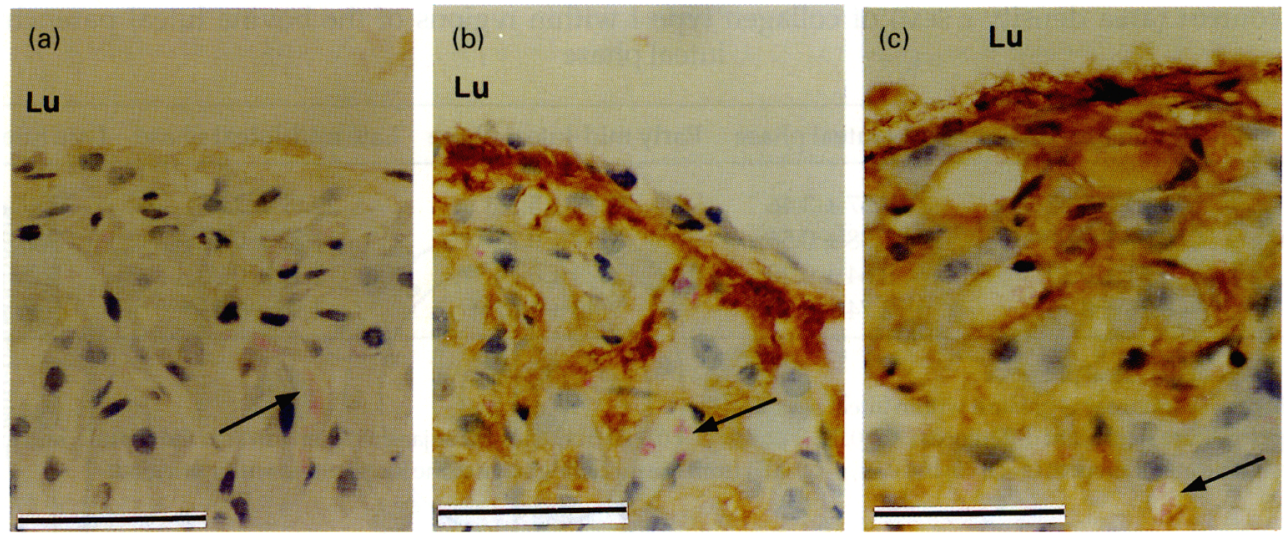

Fig. 3. Immunostaining of ovine luteal tissue on day 2 of the luteal phase. The immunolocalization of extracellular matrix components in luteal tissue is indicated by orange-brown staining. (a) Control slide treated with normal rabbit serum in place of antisera. The innermost edge of the parenchyma contained both collagen type I (b) and fibronectin (c); the fibronectin extended beyond the cellular region to form a border between the lumen and parenchyma. During early luteal development, the layer of parenchymal. cells adjacent to the lumen contained small amounts of collagen type I (b). Arrows show blood vessels; Lu, luteal lumen. Scale bars represent $50 \mu \mathrm{m}$

the post-ovulatory $(0.4 \pm 0.04 \mathrm{~g})$ period to the late mid-luteal phase $(6.8 \pm 0.39 \mathrm{~g})$, although the early mid- $(6.0 \pm 0.30 \mathrm{~g})$ and late mid-luteal phase corpora lutea were not significantly different $(P>0.1)$ from each other. The mass of the luteal tissue declined significantly between the late mid-and late luteal phase tissue $(1.9 \pm 0.35 \mathrm{~g})$. Over the 12 days of the ovine study period, there was a pattern of continually increasing luteal mass from a minimum of $115.4 \pm 9.6 \mathrm{mg}$ on day 2 to a maximum of $608.5 \pm 35.7 \mathrm{mg}$ on day 12 . The rate of the increase in luteal mass decreased towards day 12 .

\section{Qualitative immunohistological observations}

Throughout the luteal phase, the luteal capsule of both species contained abundant collagen type I and fibronectin. The collagen type I immunostaining appeared to be organized into fibrils running parallel to the outer edge of the luteal parenchyma. There was a clear demarcation between the capsule and luteal parenchyma, apparent from the relative paucity of collagen type I and fibronectin in the parenchyma and the different morphology of the cells present within each region. In most of the parenchyma, the collagen type I and fibronectin immunostaining was homogeneously distributed across the observed fields. The luminal periphery of the bovine post-ovulatory tissue had a prominent fibronectin-rich meshwork-like structure (Fig. 2c) that extended around most of the periphery and varied in thickness from 10 to $900 \mu \mathrm{m}$. This meshwork-like structure also contained von Willebrand factor (Fig. 2d), but did not contain a significant amount of collagen type I (Fig. 2b) compared with the control (Fig. 2a). There was no evidence of a meshwork-like structure at the luminal periphery of the bovine and ovine luteal tissue collected at other stages of the luteal phase.
During the first half of the luteal phase in both species, there was abundant collagen type I within the inner parenchymal region (Fig. 3b), especially adjacent to the innermost luminal edge, behind the band of strong fibronectin immunostaining located between the inner luteal tissue and the lumen (Fig. 3c). In the second half of the luteal phase, collagen type I and fibronectin were less conspicuous in the inner parenchymal region, although both were abundant in the fibroblast-rich region of 'connective' tissue at the centre of the corpus luteum in which the lumen had become occupied by the developing tissue. At all stages of luteal development, both collagen type I (Fig. 2f) and fibronectin (Fig. $2 \mathrm{~g}$ ) were distributed homogeneously in each of the defined regions.

\section{Image analysis quality control and non-specific staining for collagen type I and fibronectin}

The end-of-batch quality control slides for the collagen type I and fibronectin analyses were not significantly different $(P>0.2)$ from the start-of-batch quality control slides, and consequently no drift corrections were applied to the data. The intra-batch coefficients of variation (CV) for collagen type I and fibronectin area density were $8.6 \pm 2.3 \%$ and $7.4 \pm 2.5 \%$, respectively. Analysis of the mean area densities for the quality control slides gave inter-batch $\mathrm{CV}$ of $12.5 \pm 3.5 \%$ and $11.8 \pm 4.1 \%$ for the collagen type $\mathrm{I}$ and fibronectin immunostaining, respectively. In both species, the mean non-specific staining had an area density $<0.042$ and did not vary significantly $(P>0.2)$ between species or among the studies for either antigen.

Chi-squared comparisons among the frequency distributions of all the non-specific staining-corrected collagen type I and fibronectin analysis fields and the 
Table 1. Tissue content (area density \pm SEM) of collagen type I within regions of the bovine luteal parenchyma during the luteal phase

\begin{tabular}{lcccccc}
\hline & Post-ovulatory phase & Early luteal phase & Early mid-luteal phase & Late mid-luteal phase & Late luteal phase & $P$ value \\
\hline Capsule & $11.99 \pm 1.52$ & $19.57 \pm 3.46$ & $38.23 \pm 5.25^{\mathrm{b}}$ & $29.57 \pm 2.35$ & $27.46 \pm 1.18$ & $<0.01$ \\
Outer parenchyma & $0.37 \pm 0.08^{\mathrm{C}}$ & $1.38 \pm 0.56^{\mathrm{C}}$ & $1.14 \pm 0.35^{\mathrm{C}}$ & $1.83 \pm 0.81^{\mathrm{C}}$ & $3.41 \pm 1.30^{\mathrm{C}}$ & $>0.05$ \\
Mid-parenchyma & $0.51 \pm 0.12$ & $0.64 \pm 0.20$ & $0.73 \pm 0.24$ & $1.13 \pm 0.70$ & $5.25 \pm 0.95$ & $>0.05$ \\
Inner parenchyma & $3.26 \pm 0.75$ & $2.74 \pm 0.83$ & $7.43 \pm 1.02^{\mathrm{Aa}}$ & $4.54 \pm 1.13^{\mathrm{A}}$ & $5.19 \pm 1.16$ & $<0.05$ \\
\hline
\end{tabular}

$n=5$ animals for each stage of the luteal phase.

$P=$ ANOVA probability that variance was greatest within luteal periods.

Upper case superscripts indicate significant differences $(\mathrm{A}<0.05, \mathrm{~B}<0.01, \mathrm{C}<0.005)$ from the next adjacent region towards the capsule, and lower case superscripts indicate significant differences $(a<0.05, b<0.01, c<0.005)$ from the preceding stage of the luteal phase within a region.

Table 2. Tissue content (area density \pm SEM) of fibronectin within regions of the bovine luteal parenchyma during the luteal phase

\begin{tabular}{lcccccc}
\hline & Post-ovulatory phase & Early luteal phase & Early mid-luteal phase & Late mid-luteal phase & Late luteal phase & $P$ value \\
\hline Capsule & $39.21 \pm 2.25$ & $28.89 \pm 1.43$ & $33.85 \pm 2.30$ & $36.34 \pm 3.65$ & $28.81 \pm 1.63$ & $<0.05$ \\
Outer parenchyma & $24.52 \pm 1.62^{\mathrm{B}}$ & $22.13 \pm 1.18^{\AA}$ & $14.07 \pm 1.52^{\mathrm{Ba}}$ & $16.79 \pm 1.21^{\mathrm{B}}$ & $9.24 \pm 1.76^{\mathrm{C}}$ & $<0.05$ \\
Mid-parenchyma & $22.42 \pm 1.54$ & $20.71 \pm 1.36$ & $13.83 \pm 1.49^{\mathrm{a}}$ & $14.17 \pm 1.56$ & $10.25 \pm 1.38$ & $<0.05$ \\
Inner parenchyma & $28.69 \pm 1.65$ & $31.52 \pm 2.22^{\AA}$ & $29.23 \pm 1.76^{\mathrm{B}}$ & $20.90 \pm 1.70^{\mathrm{A}}$ & $15.42 \pm 1.65$ & $<0.05$ \\
\hline
\end{tabular}

$n=5$ animals for each stage of the luteal phase.

$P=$ ANOVA probability that variance was greatest within luteal periods.

Upper case superscripts indicate significant differences $(A<0.05, B<0.01, C<0.005)$ from the next adjacent region towards the capsule, and lower case

superscripts indicate significant differences $(a<0.05, b<0.01, c<0.005)$ from the preceding stage of the luteal phase within a region.

theoretical frequency distributions indicated that the image analysis data for both antigens were normally distributed $(P<0.05 \%)$.

\section{Image analysis of collagen type I and fibronectin immunostaining}

Bovine. In all stages of the luteal phase, the amount of collagen type I was greater in the capsule region than in the respective parenchymal regions (Table 1). The amount of collagen type I in the capsule increased over threefold from a minimum value in the post-ovulatory period to a maximum value in the early mid-luteal phase. There was no significant change in the amount of collagen type I in the outer and midparenchymal regions throughout the luteal phase. The minimum collagen type I area densities for both of these regions occurred during the post-ovulatory period and the maximum area density occurred during the late luteal phase. The amount of collagen type I in the inner parenchyma was between four- and tenfold greater than in the midparenchymal region throughout most of the luteal phase. The maximum amount of collagen type $I$ in the inner parenchymal region occurred during the early mid-luteal period.

The amount of fibronectin in the bovine capsule region was 1.5- to 3.0-fold greater than in the adjacent outer parenchymal region throughout the luteal phase (Table 2). There was no significant pattern in the amount of fibronectin in the capsule during the luteal phase. In the outer and midparenchymal regions, the amount of fibronectin was similar in all periods of the luteal phase studied. Within both of these two regions, the amount of fibronectin decreased by more than $50 \%$ from a maximum value in the post-ovulatory period to a miniumum value in the late luteal phase. The inner parenchymal region contained more fibronectin than the respective mid-parenchymal regions throughout the luteal phase, and the differences were significant in the early and early mid-luteal phase tissues. The amount of fibronectin in the inner parenchyma decreased approximately twofold from a maximum value in early luteal tissue to a minimum value in the late luteal tissue.

The results for the distribution of fibronectin and collagen type I in the bovine corpus luteum during luteal development are summarized (Fig. 4).

Ovine. The capsule region contained six- to tenfold more collagen type I than the adjacent outer parenchymal region, and the maximum amount (day 7 ) was $58 \%$ greater than the minimum amount (day 2; Table 3). Between day 7 and day 12 , the amount of collagen type I in the capsule decreased by $26 \%$. The outer and mid-parenchymal regions contained a similar amount of collagen type I on all days of the luteal phase studied. Within both of these regions, the amount of collagen type I in the tissue increased over twofold between the minimum values on day 2 and the maximum values on day 7 , and declined thereafter. Between day 2 and day 9 , the inner parenchymal region contained 3.5 - to 12 -fold more collagen type I than the mid-parenchymal region, and the magnitude of the difference between the two regions decreased with the age of the luteal tissue. The maximum amount of collagen type I in the inner parenchymal region 

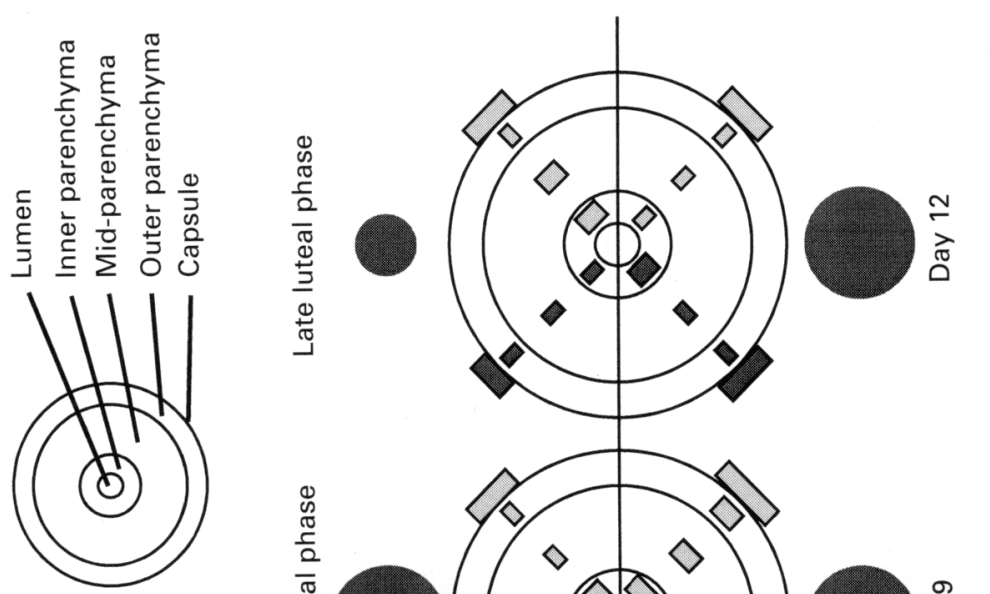

范落

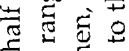

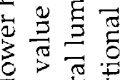

焉范范

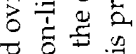

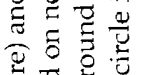

$\Rightarrow \begin{array}{ll}0 \\ 0\end{array}$

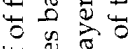

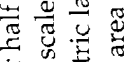

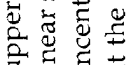

运苛

苛是

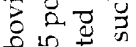

पे

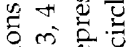

员

$\Xi \bar{d}$ 至

苞产

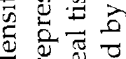

$\approx$

(⿻)丨

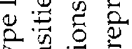

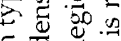
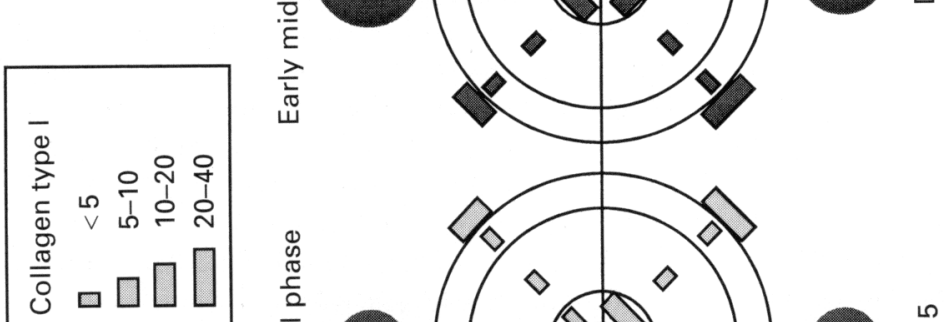

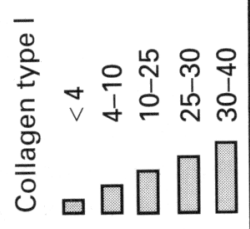

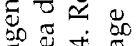

焉导士

苦造焉

흥 훙

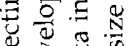

远 $\frac{\pi}{0}$

㤩焉焉

क 3 品

है की की

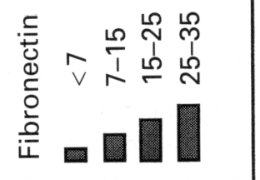

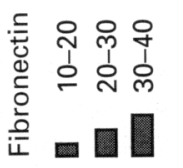

:

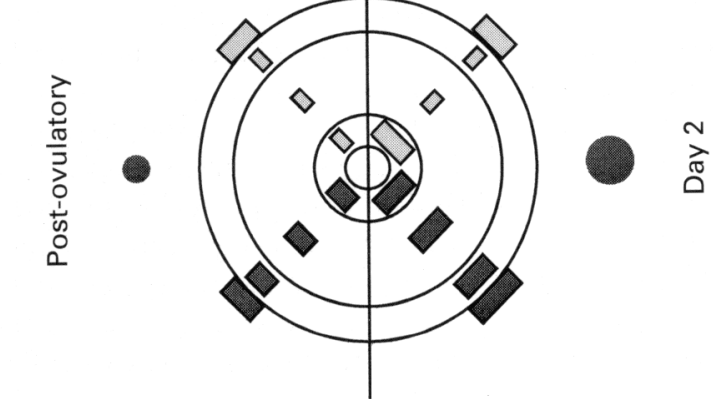

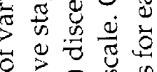

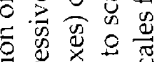

过

范焉

菏芯苋

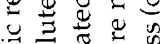

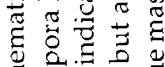

รั

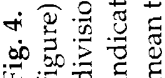


Table 3. Tissue content (area density \pm SEM) of collagen type I within various regions of the ovine luteal parenchyma during the luteal phase

\begin{tabular}{|c|c|c|c|c|c|c|}
\hline & Day 2 & Day 5 & Day 7 & Day 9 & Day 12 & $P$ value \\
\hline Capsule & $22.52 \pm 2.04$ & $29.52 \pm 2.32^{\mathrm{a}}$ & $38.56 \pm 2.61^{\mathrm{a}}$ & $37.56 \pm 2.29$ & $28.47 \pm 1.92^{\mathrm{a}}$ & $<0.05$ \\
\hline Outer parenchyma & $2.51 \pm 1.09$ & $2.86 \pm 1.26^{\mathrm{C}}$ & $6.50 \pm 1.73^{\mathrm{Ca}}$ & $5.01 \pm 0.97^{\mathrm{C}}$ & $3.17 \pm 0.73^{\mathrm{Ca}}$ & $<0.05$ \\
\hline Inner parenchyma & $21.05 \pm 2.21^{\mathrm{C}}$ & $27.00 \pm 2.36^{\mathrm{C}}$ & $19.84 \pm 2.14^{\mathrm{Ca}}$ & $14.91 \pm 2.02^{\mathrm{C}}$ & $3.75 \pm 0.92^{b}$ & $<0.01$ \\
\hline
\end{tabular}

$n=4$ animals for each stage of the luteal phase.

$P=$ ANOVA probability that variance was greatest within luteal periods.

Upper case superscripts indicate significant differences $(A<0.05, B<0.01, C<0.005)$ from the next adjacent region towards the capsule, and lower case

superscripts indicate significant differences $(a<0.05, b<0.01, c<0.005)$ from the preceding stage of the luteal phase within a region.

Table 4. Tissue content (area density \pm SEM) of fibronectin within various regions of the ovine luteal parenchyma during the luteal phase

\begin{tabular}{|c|c|c|c|c|c|c|}
\hline & Day 2 & Day 5 & Day 7 & Day 9 & Day 12 & $P$ value \\
\hline Capsule & $28.10 \pm 1.45$ & $32.91 \pm 1.93$ & $27.37 \pm 1.78$ & $25.30 \pm 1.27$ & $30.21 \pm 1.34$ & $<0.01$ \\
\hline Outer parenchyma & $16.78 \pm 1.62^{A}$ & $9.68 \pm 1.15^{\mathrm{Ca}}$ & $3.00 \pm 1.03^{\mathrm{Cit}}$ & $2.91 \pm 0.87^{C}$ & $3.80 \pm 1.61^{C}$ & $<0.05$ \\
\hline Inner parenchyma & $19.37 \pm 2.08$ & $21.48 \pm 1.98^{\mathrm{A}}$ & $9.36 \pm 1.26^{b}$ & $11.05 \pm 1.53^{\mathrm{B}}$ & $8.71 \pm 1.67$ & $<0.01$ \\
\hline
\end{tabular}

$n=4$ animals for each stage of the luteal phase.

$P=$ ANOVA probability that variance was greatest within luteal periods.

Upper case superscripts indicate significant differences $(\mathrm{A}<0.05, \mathrm{~B}<0.01, \mathrm{C}<0.005)$ from the next adjacent region towards the capsule, and lower case

superscripts indicate significant differences $(a<0.05, b<0.01, c<0.005)$ from the preceding stage of the luteal phase within a region.

was observed in the tissue collected on day 5 , and decreased by approximately sevenfold to a minimum value in the tissue collected on day 12 .

On all days of the luteal phase studied, the capsule region contained more fibronectin than the outer parenchymal region (Table 4). In both the outer and mid-parenchymal regions, the maximum amount of fibronectin was observed in tissue from day 2. Between day 2 and day 7 , the amount of fibronectin in the outer and mid-parenchymal regions decreased by 5.6-fold and 3.4-fold, respectively, and did not vary significantly between these two regions thereafter. Throughout the luteal phase, the inner parenchymal region contained more fibronectin than the mid-parenchymal region, and the amount differed significantly on days 5 and 9. The amount of fibronectin in the inner parenchymal region reached a maximum value on day 5 and decreased 2.3-fold by day 7 ; it did not vary significantly thereafter.

The results for the distribution of fibronectin and collagen type I in the ovine corpus luteum during luteal development are summarized (Fig. 4).

\section{Detection of collagen type IV in ovine luteal tissue}

The limited data on the distribution of collagen type IV did not permit statistical analysis, but a number of observations were possible. It was apparent that not all large luteal cells were associated with collagen type IV-containing basal lamina (Table 5, Fig. 5b,c). A maximum of $4 \%$ of the large luteal cells in a parenchymal region contained collagen type IV immunostaining that extended more than halfway around the cell. The large luteal cells that had some associated collagen type IV were not distributed uniformly throughout the parenchyma on days 2 and 12. Finally, although the distribution of large luteal cells associated with collagen type IV could not be analysed statistically among the different days, it appeared that the distribution of these cells changed throughout the luteal phase. On day 2, the outermost region of luteal parenchyma contained the greatest number of large luteal cells with associated collagen type IV, while these cells were distributed evenly throughout the luteal parenchyma on day 7 and were more numerous in the innermost region on day 12.

\section{Discussion}

The masses of the bovine corpora lutea observed during the various stages of the luteal phase were similar to those reported previously (Wathes et al., 1984; Luck and Zhao, 1993; Zheng et al., 1994; Ricken et al., 1995). The observed ovine luteal masses were slightly greater than those observed in previous studies (Jablonka-Shariff et al., 1993; Grazul-Bilska et al., 1992). These differences are probably the result of the use of different breeds. The increase in luteal mass, which excluded any residual luminal fluid, indicated that de novo tissue formation was taking place during the first half of the luteal phase in both species.

The present study has confirmed that abundant collagen type I is present in the bovine as well as in the ovine luteal capsule, and that the amount in the parenchyma changes throughout the luteal phase. The detection of immunoreactive 
Table 5. Percentage of large luteal cells with associated collagen type IV within different regions of the ovine luteal parenchyma on days 2,7 and 12 of the luteal phase

\begin{tabular}{lcccc}
\hline & \multicolumn{4}{c}{ Percentage of the distance between the outer and inner parenchymal peripheries } \\
\cline { 2 - 5 } Day of the luteal phase & $0-10$ & $11-50$ & $51-90$ & $91-100$ \\
\hline 2 & 66.7 & 44.9 & 44.8 & 44.4 \\
7 & 68.8 & 60.7 & 67.6 & 56.0 \\
12 & 0.0 & 35.0 & 30.4 & 80.0 \\
\hline
\end{tabular}
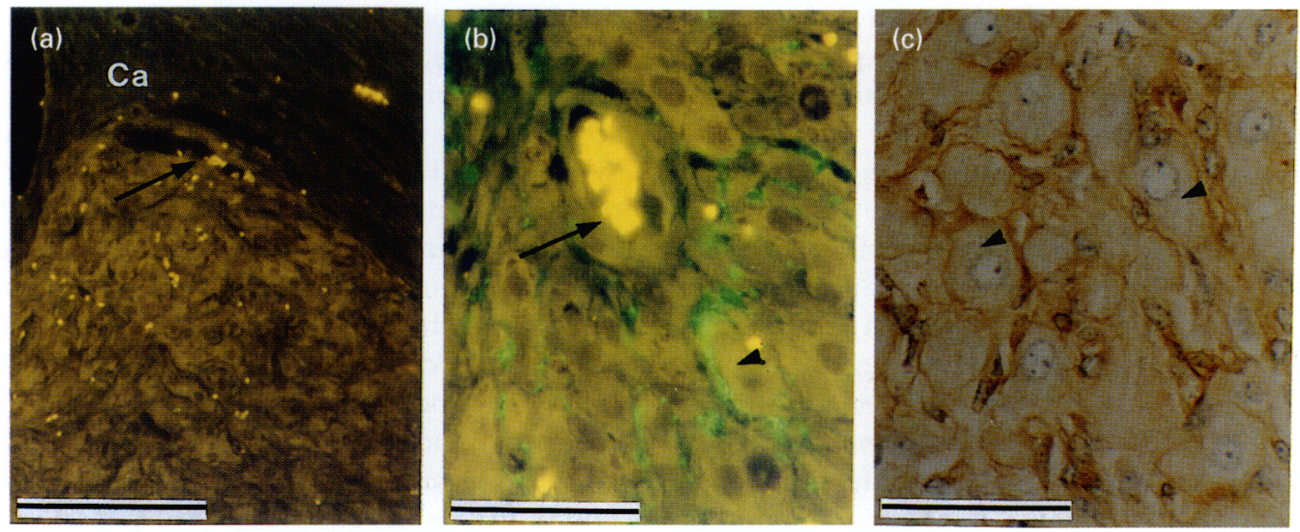

Fig. 5. Immunostaining of bovine and ovine luteal tissue during various stages of the luteal phase. $(a, b)$ Day 7 of the ovine luteal phase; (c) bovine early mid-luteal phase. The distribution of extracellular matrix components is indicated by immunohistological orange-brown staining (c) and by immunofluorescent green staining (b). (a) Control slide treated with normal rabbit serum in place of antisera. In the ovine (b) and bovine (c) luteal parenchyma, some of the large luteal cells had an associated basal lamina, as indicated by the presence of collagen type IV (arrowheads), which typically extended less than halfway around the cells. Arrows show blood vessels; Ca, luteal capsule. Scale bars represent (a) $200 \mu \mathrm{m}$ and (b,c) $50 \mu \mathrm{m}$.

collagen type IV in the ovine corpus luteum in the present study supports ultrastructural observations (Deane et al., 1966; O'Shea et al., 1979; Farin et al., 1986; Kenny et al., 1989) and confirms the lack of sensitivity of previous detection systems (Luck and Zhao, 1993). There have been no previous systematic studies of the distribution of specific ECM proteins in the luteal tissue of any species. The present observations of the distributions of collagen type I and fibronectin in the ruminant luteal parenchyma therefore provide the first opportunity to gain insight into the development of the luteal ECM.

Measurement of fibronectin and collagen type I area density revealed that both proteins were most abundant in the capsule region, that the area density of fibronectin in this region was high throughout the luteal phase, and that maximal values for collagen type I in the capsule were attained by the early mid-luteal phase (bovine) and days 7-9 (ovine). Since the masses of the corpora lutea continued to increase beyond these stages, it is clear that a considerable net synthesis of these proteins must have taken place in the capsule region throughout the active part of the luteal phase.

The outer region of the parenchyma adjacent to the capsule showed little change in collagen type I area density, except for a small increase on days 7 and 9 of the ovine cycle and despite a concurrent thinning of fibronectin in the same region. A similar pattern was observed in the midparenchymal region. As in the capsule, these developments in growing tissue indicate that active remodelling of both proteins is taking place. In the ovine tissue, the increase in collagen area density in the mid-and outer parenchyma up to day 9 demonstrates that protein production either matches or exceeds any concurrent increase in the number or size of cells in the same tissue.

Changes in protein area density in inner parenchymal tissue showed a more complex pattern. In the bovine tissue, the amount of collagen type I was low during the early part of the luteal phase, but increased in the mid-luteal phase as the luteal tissue neared its maximum mass. Fibronectin content increased as the tissue grew, but decreased markedly in the mature (late mid-luteal phase) and late phase tissue. These changes indicate a positive association between tissue development and fibronectin in this region. In the ovine tissue, inner parenchymal collagen type I was abundant in growing tissue, but the amount decreased markedly between day 9 and day 12 as the rate of tissue growth decreased. The area density of fibronectin in this region was high during the 
first 5 days of the ovine luteal phase, but then decreased and remained at a roughly constant value up to day 12 . These changes also indicate that fibronectin synthesis is prevalent in the inner parenchyma during growth of the corpus luteum, but that in sheep, the rate of inner parenchymal collagen type I synthesis reaches a peak earlier (relative to growth of the corpus luteum) than it does in cows.

The results of this study indicate that collagen type I and fibronectin deposition and turnover are regulated differentially in the corpus luteum and that the rate of ECM remodelling is region specific. This implies that the development of luteal tissue is subject to regulation by autocrine or paracrine, rather than endocrine, factors. It is apparent that the most active turnover occurs in the inner parenchyma and that changes in the mid- and outer parenchymal regions succeed rather than precede changes in that region. A further possibility is that reorganization leads to 'movement' of tissue between the three (artificially designated) regions of the parenchyma during growth.

In both species studied, there was a more rapid decrease in the amount of fibronectin in the outer and mid-parenchymal regions than in the inner (adjacent to the lumen) parenchymal region. Furthermore, the inner parenchymal regions of both species contained abundant fibronectin, especially during the first half of the luteal phase. These arrangements strongly resemble wound repair, in which the proliferating edge of the granulation tissue contains a greater amount of fibronectin than the more mature tissue behind it. Moreover, in early stage tissue, the region of parenchyma adjacent to the lumen was relatively free of collagen type I, despite the presence of abundant fibronectin. Collagen type I only became more apparent later in development, especially at the innermost edges of the luteal parenchyma. These observations lead to the tentative conclusion that growth of the corpus luteum involves the formation of new tissue close to the lumen, followed by a net 'movement' of tissue towards the periphery. Although remodelling continues in all regions, the outer tissue is older than the tissue closer to the centre. However, it must be noted that a simplified model of luteal structure has been used: the parenchyma is actually segmented, and the inner parenchyma includes tissue at the margins of the segments as well as that adjacent to the central lumen.

Ovulation, the catastrophic tissue event that immediately precedes luteinization, has been likened to an inflammatory process (Espey, 1980). Similarly, it is possible to consider luteinization as a process of wound repair. Classical wound repair is one of the best understood examples of tissue remodelling in healthy adult mammals and involves a well described sequence of ECM deposition, leading to the formation of new tissue; this process is described as granulation. During the early stages, granulation tissue is rich in fibronectin but low in collagen. Subsequently, the amount of fibronectin decreases, and fibrillar collagen is deposited as a collagen type III-rich matrix, which is then replaced by collagen type I (Bailey et al., 1975; Gabbiana et al., 1976; Gay et al., 1978; Grinnell et al., 1981; Williams et al., 1984).

A similar type of structural evolution from fibronectin to collagen appears to take place in the corpus luteum. The analogy with wound repair is supported by the observation of blood clots in the luteal lumen and the presence of abundant von Willebrand factor in the lumen (indicative of the presence of platelets and endothelial cells) at early stages of development. Therefore, it is hypothesized that fibronectin plays a crucial role in defining the structural arrangement of the developing corpus luteum. This role is of continuing importance at the luminal edge while new tissue is formed and is of transient importance in the mid- and outer parenchyma while the tissue is relatively soft and unstructured (bovine: post-ovulatory and early luteal phase; ovine: days 2 and 5). From this hypothesis, it would be predicted that luteal regions with abundant fibronectin should also contain abundant collagen type III.

During the maturation of granulation tissue there is an initial overproduction of collagen (types III and I), accompanied by an increase in matrix metalloproteinase (MMP) activity and high concentrations of tissue inhibitors of metalloproteinases (TIMPs) (Moses et al., 1996). Similarly, in the ovary, initiation of collagen synthesis appears to be an early event that is associated with follicle rupture (Nagai et al., 1998). Although fibrillar collagen-specific MMP activity has not been observed in the corpus luteum of any species, TIMPs are known to form a major proportion of the total protein produced in bovine (Freudenstein et al., 1990; Juengel et al., 1994) and ovine (Smith and Moor, 1991; Smith et al., 1993) luteal tissue. The presence of this active enzyme system indicates that tight control of the remodelling process is required in the corpus luteum. The inner parenchymal region appears to be a site of de novo tissue formation and active tissue remodelling, and it is therefore predicted that this region has higher fibrillar collagen-specific MMP activity and higher extracellular TIMP-1 concentrations than other regions.

Collagen type IV is located exclusively in structures of the basal lamina (Merker, 1994) and it is apparent from the observations of the present study that some ovine large luteal cells possess a basal lamina. Although it is possible that some of the observed collagen type IV was associated with endothelial basal lamina, any collagen type IV that was obviously associated with capillaries was excluded from the analysis. This is the first observation of basal laminae associated with ovine large luteal cells. As the majority of large luteal cells were only partially surrounded by this structure, it is likely that complete containment by a basal lamina is not required for these cells to function and retain their phenotype. It is also possible that a three-dimensional analysis would show the basal lamina organizing large luteal cells into multicellular groups, rather than isolating individual cells. Although this study could not identify which cells were responsible for the synthesis and secretion of collagen type IV, observations of cultured luteinized granulosa cells indicate that the large luteal cells may be a source of this component of the basal lamina (Zhao and Luck, 1995, 1996; Rodgers et al., 1996). The observation that collagen type IV is present around rat granulosa-derived cells (Matsushima et al., 1996) also indicates that large luteal cells may be the origin of basal lamina. There are several explanations for the discrepancy between these observations and ultrastructural studies that show most large luteal cells 
have a basal lamina that surrounds the cell completely (Deane et al., 1966; O'Shea et al., 1979, 1990; Fields et al., 1985, 1992; Farin et al., 1986; Kenny et al., 1989; Sawyer, 1995). Firstly, there is a difference in magnification; ultrastructural studies are able to differentiate finer details. In addition, there were differences in design; there was no indication of a systematic approach in the ultrastructural studies. Given the observed proportion of large luteal cells that have a collagen type IV-containing basal lamina, current models of basal lamina formation (Leblond and Inoue, 1989; Merker, 1994), and the distribution of these cells during luteal development, it is likely that the formation of a basal lamina is a normal, but possibly transient, component of the ovine large luteal cell phenotype, which serves to divide the parenchyma into enclaves rather than to isolate individual cells. The role that the basal lamina plays in the function of large luteal cells remains to be determined.

In summary, this study provided immunohistochemical evidence that bovine and ovine luteal tissue contains collagen type I, collagen type IV and fibronectin. The abundance of these proteins varies throughout the luteal parenchyma, and local concentrations fluctuate during the different stages of luteal development. The distribution of collagen type IV indicates that not all large luteal cells have an associated basal lamina and, in the majority of these cells, the basal lamina extends less than halfway around the perimeter. Several features of the ECM distribution in developing luteal tissue, including the presence of a postovulatory meshwork rich in fibronectin and von Willebrand factor and the existence of sequential patterns of collagen type I and fibronectin, are strongly reminiscent of granulation tissue. This indicates that luteinization may be best understood as a wound repair-like process that succeeds the tissue disturbance associated with follicle rupture and ovulation.

The authors are indebted to the following for their contributions to this work: A. M. Clarkson and L. Sheldrick for provision of the day 9 ovine ovarian tissue; G. E. Mann for the bovine post-ovulatory tissue; D. Edwards and the staff of the Joint Animal Breeding Unit for the care of the animals; J. Corbett for killing and dissecting the animals and acquisition of abattoir-derived material; D. J. Hartmann (Insitut Pasteur de Lyon) for the gift of antisera to collagen types I and IV; S. Fleming (NURTURE, Queen's Medical Centre, Nottingham) for facilitating access to a line-scanning confocal microscope; T. Gray (Pathology, Queen's Medical Centre, Nottingham) for access to the image analysis system; and J. Craigon (Environmental Science, University of Nottingham) for advice on statistical analysis.

\section{References}

Acritopoulou S, Haresign W and Lamming GE (1978) Time of ovulation in ewes after treatment with a prostaglandin F-2a analogue Journal of Reproduction and Fertility 54 189-191

Amenta PS and Martinez-Hernandez A (1987) Specific methods for electron immunohistochemistry Methods in Enzymology 145 133-148

Archbald LF, Al-Bagdadi F and Godke RA (1981) A light and electron microscope study of the periparturient bovine corpus luteum Theriogenology $1627-37$

Bailey AJ, Sims TJ, LeLous M and Bazin S (1975) Collagen polymorphism in experimental granulation tissue Biochemical and Biophysical Research Communications $661160-1165$
Corner GW, Jr (1956) The histological dating of the human corpus luteum of menstruation American Journal of Anatomy 98 377-392

Deane HW, Hay MF, Moor RM, Rowson LEA and Short RV (1966) The corpus luteum of the sheep: relationships between morphology and function during the oestrous cycle Acta Endocrinologica 51 245-263

Deichert U, Kuhn C, Chari S, Sturm G and Daume E (1987) Correlations of steroid contents with the size and form of bovine corpus luteum by ultrasound Acta Endocrinologica 114120

Donaldson L and Hansel W (1965) Histological study of bovine corpora lutea Journal of Dairy Science 48 905-909

Espey LL (1980) Ovulation as an inflammatory reaction - a hypothesis Biology of Reproduction 22 73-106

Farin CE, Moeller CL, Sawyer HR, Gamboni F and Niswender GD (1986) Morphometric analysis of cell types in the ovine corpus luteum throughout the estrous cycle Biology of Reproduction 35 1299-1308

Fields MJ, Dubois W and Fields PA (1985) Dynamic features of luteal secretory granules: ultrastructural changes during the course of pregnancy Endocrinology 117 1675-1682

Fields MJ, Barros CM, Watkins WB and Fields PA (1992) Characterization of large luteal cells and their secretory granules during the estrous cycle of the cow Biology of Reproduction 46 535-545

Freudenstein J, Wagner S, Luck MR, Einspanier R and Scheit KH (1990) mRNA of bovine tissue inhibitor of metalloproteinases: sequence and expression in bovine ovarian tissue Biochemical and Biophysical Research Communications 171 250-256

Gabbiana G, Lelous MAJB, Bazin S and Delaunay A (1976) Collagen and myofibroblasts of granulation tissue: a chemical, ultrastructural and immunologic study Virchows Archive B Cell Pathology 21 133-145

Gay S, Viljanto J, Raekallio J and Penttinen R (1978) Collagen types in early phases of wound healing in children Acta Chirurgica Scandinavica 144 205-211

Gemmell RT, Stacy BD and Thorburn GD (1974) Ultrastructure study of secretory granules in the corpus luteum of the sheep during the estrous cycle Biology of Reproduction 11 447-462

Grazul-Bilska AT, Redmer DA, Killilea SD, Kraft KC and Reynolds LP (1992) Production of mitogenic factors by ovine corpora lutea throughout the estrous cycle Endocrinology 1303625-3632

Grinnell F, Billingham RE and Burgess L (1981) Distribution of fibronectin during wound healing in vivo. Journal of investigative Dermatology 76 181-189

Hadek R (1958) Morphological and histochemical study on the ovary of the sheep American Journal of Veterinary Research October 873-880

Hughes A and Grawoig D (1971) The chi-square distribution and statistical inference. In Statistics: A Foundation for Analysis pp 223-242. AddisonWesley, London

Hulmes DJS (1992) The collagen superfamily - diverse structures and assemblies Essays in Biochemistry $2749-67$

Ireland JJ, Murphee RL and Coulson PB (1980) Accuracy of predicting stages of bovine estrous cycle by gross appearance of the corpus luteum Journal of Dairy Science 63 155-160

Jablonka-Shariff A, Grazul-Bilska AT, Redmer DA and Reynolds LP (1993) Growth and cellular proliferation of ovine corpora lutea throughout the estrous cycle Endocrinology 133 1871-1879

Juengel JL, Smith GW, Smith MF, Youngquist RS and Garverick HA (1994) Pattern of protein production by bovine corpora lutea during luteolysis and characterization of expression of two major secretory products of regressing corpora lutea Journal of Reproduction and Fertility 100 515-520

Kenny N, Farin CE and Niswender GD (1989) Morphometric quantification of mitochondria in the two steroidogenic ovine luteal cell types Biology of Reproduction 40 191-196

Leblond CP and Inoue S (1989) Structure, composition, and assembly of basement membrane American Journal of Anatomy 185 367-390

Luck MR (1994) The gonadal extracellular matrix Oxford Reviews of Reproductive Biology 1633-85

Luck MR and Zhao Y (1993) Identification and measurement of collagen in the bovine corpus luteum and its relationship with ascorbic acid and tissue development Journal of Reproduction and Fertility 99 647-652

Luck MR, Zhao Y and Silvester LM (1995) Identification and localization of collagen type-I and type-IV in the ruminant follicle and corpus luteum Journal of Reproduction and Fertility Supplement 49 517-521

Matsushima T, Fukuda Y, Tsukada K and Yamanaka N (1996) The extracellular matrices and vascularization of the developing corpus luteum in rats Journal of Submicroscopic Cytology and Pathology 28 441-455

Mauger A, Emond H, Hartmann DJ, Foidart JM and Sengel P (1987) 
Immunofluorescent localization of collagen types I, III and IV, fibronectin, laminin and basement membrane proteoglycans in developing mouse skin Roux's Archives of Developmental Biology 196 295-302

Merker HJ (1994) Morphology of the basement membrane Microscopy Research and Technique 28 95-124

Moses MA, Marikovsky M, Harper JW, Vogt P, Eriksson E, Klagsbrun M and Langer R (1996) Temporal study of the activity of matrix metalloproteinases and their endogenous inhibitors during wound healing Journal of Cellular Biochemistry $60379-386$

Myers JC, Li DQ, Bageris A, Abraham V, Dion AS and Amenta PS (1997) Biochemical and immunohistochemical characterization of human type XIX defines a novel class of basement membrane zone collagens American Journal of Pathology 151 1729-1740

Nagai R, Tanaka N, Fukumatsu Y, Katabuchi H and Okamura H (1998) Spatio-temporal changes of prolyl 4-hydroxylase in granulosa cells during ovulation in eCG-hCG-treated immature rat ovaries journal of Reproduction and Fertility $113349-354$

O'Shea JD, Cran DG and Hay MF (1979) The small luteal cell of the sheep Journal of Anatomy 128 239-251

O'Shea JD, Rodgers RJ, McCoy K and D'Occhio MJ (1990) Ultrastructural cytology of the cyclic corpus luteum of the cow Acta Anatomica 138 154-165

Parkinson TJ, Turvey A and Jenner LJ (1994) A morphometric analysis of the corpus luteum of the cow during the estrous cycle and early pregnancy Theriogenology 41 1115-1126

Parry DM, Willcox DL and Thorburn GD (1980) Ultrastructural and cytochemical study of the bovine corpus luteum Journal of Reproduction and Fertility 60 349-357

Priedkalns J, Weber AF and Zemjanis R (1968) Qualitative and quantitative morphological studies of the cells of the membrana granulosa, theca interna and corpus luteum of the bovine ovary Zeitschrift fiir Zellforschung 85 501-520

Redmer DA and Reynolds LP (1996) Angiogenesis in the ovary Reviews of Reproduction 1 182-192

Ricard-Blum S, Tiollier J, Dodille MP, Hartmann DJ, Magloire H, Garrone R, Ville $G$ and Herbage D (1985) Collagen heterogenicity in bovine and human cartilage. In Osteoarthritis - Current Clinical and Fundanental Problems pp 123-133 Ed. JG Peyron. Primard, Paris

Ricken AM, Spanel-Borowski K, Saxer M and Huber PR (1995) Cytokeratin expression in bovine corpora lutea Histochemistry 103 345-354

Rodgers RJ, Vella CA, Rodgers HF, Scott K and Lavranos TC (1996) Production of extracellular matrix, fibronectin and steroidogenic enzymes, and growth of bovine granulosa cells in anchorage-independent culture Reproduction Fertility and Development 8 249-257
Ruggeri ZM (1991) Structure and function of von Willebrand factor: relationship to von Willebrand's disease Mayo Clinic Proceedings 66 847-861

Saarela J, Ylikarppa R, Rehn M, Purmonen S and Pihlajaniemi T (1998) Complete primary structure of two variant forms of human type XVIIl collagen and tissue-specific differences in the expression of the corresponding transcripts Matrix Biology 16 319-328

Sawyer HR (1995) Structural and functional properties of the corpus luteum of pregnancy Journal of Reproduction and Fertility Supplement 49 97-110

Shiina K (1990) Collagen and acid glycosaminoglycans in bovine tunica albuginea during ovulatory cycle Nippon Sanka Fujinka Gakkai Zasshi-Acta Obstetrica et Gynaecologica Japonica 42 1510-1517

Silvester LM (1997) Development of the Luteal Extracellular Matrix in Dontestic Ruminants MPhil Thesis, University of Nottingham

Silwer J (1973) von Willebrand's disease in Sweden Acta Paediatrica Scandia Supplement 238 1-159

Smith GW, Moor RM and Smith MF (1993) Identification of a $30000 \mathrm{M}$ polypeptide secreted by cultured ovine granulosa cells and luteal tissue as a tissue inhibitor of metalloproteinases Biology of Reproduction 48 125-132

Smith MF and Moor RM (1991) Secretion of a putative metalloproteinase inhibitor by ovine granulosa cells and luteal tissue Jourhal of Reproduction and Fertility 91 627-635

Wathes DC, Swann RW and Pickering BT (1984) Variations in oxytocin, vasopressin and neurophysin concentrations in the bovine ovary during the oestrus cycle and pregnancy Journal of Reproduction and Fertility 71 551-557

Williams IF, McCullagh KG and Silver IA (1984) The distribution of types I and III collagen and fibronectin in the healing equine tendon Connective Tissue Research 12 211-227

Yamada M and Gentry PA (1995) Hemostatic profile of bovine ovarian follicular fluid Canadian Journal of Physiology and Pharmacology 73 624-629

Zhao Y and Luck MR (1995) Gene expression and protein distribution of collagen, fibronectin and laminin in bovine follicles and corpora lutea Journal of Reproduction and Fertility 104 115-123

Zhao Y and Luck MR (1996) Bovine granulosa cells express extracellular matrix proteins and their regulators during luteinization in culture Reproduction Fertility and Development $8259-266$

Zheng J, Redmer DA and Reynolds L,P (1993) Vascular development and heparin-binding growth factors in the bovine corpus luteum at several stages of the estrous cycle Biology of Reproduction 49 1177-1189

Zheng J, Fricke PM, Reynolds LP and Redmer DA (1994) Evaluation of growth, cell proliferation and cell death in bovine corpora lutea throughout the estrous cycle Biology of Reproduction 51 623-632 